\title{
Circulating leptin levels are associated with physical activity or physical fitness in Japanese
}

\author{
Nobuyuki Miyatake $\cdot$ Haruka Murakami • \\ Ryoko Kawakami · Izumi Tabata $\cdot$ Motohiko Miyachi • \\ The NEXIS Study Group
}

Received: 28 April 2014/ Accepted: 24 June 2014/Published online: 22 July 2014

(c) The Japanese Society for Hygiene 2014

\begin{abstract}
Objective The aim of this study was to evaluate the link between circulating leptin levels and physical activity and/ or physical fitness in apparently healthy Japanese.

Methods A total of 85 men and 111 women who were not taking any medication were enrolled in this cross-sectional study. Circulating leptin levels, physical activity measured by tri-axial accelerometers and peak oxygen uptake were evaluated. We also assessed anthropometric data, blood pressure, blood examinations and energy intake.

Results Circulating leptin levels were $3.2 \pm 2.3 \mathrm{ng} / \mathrm{mL}$ in men and $5.9 \pm 3.8 \mathrm{ng} / \mathrm{mL}$ in women. Circulating leptin levels were significantly and positively correlated with body weight, body mass index, abdominal circumference, insulin and the homeostasis model assessment index, and significantly and negatively correlated with peak oxygen uptake in both sexes. Stepwise multiple regression showed that peak oxygen uptake in men and physical activity evaluated by $\sum[$ metabolic equivalents $\times$ h per week $($ METs $h / w)$ ] in women were determinant factors for circulating leptin levels after adjusting for confounding factors.
\end{abstract}

N. Miyatake $(\square)$

Department of Hygiene, Faculty of Medicine, Kagawa

University, Miki, Kagawa 761-0793, Japan

e-mail: miyarin@med.kagawa-u.ac.jp

H. Murakami · R. Kawakami · M. Miyachi

Department of Health Promotion and Exercise, National Institute of Health and Nutrition, Tokyo 162-8636, Japan

I. Tabata

College of Sport and Health Science, Ritsumeikan University,

Kusatsu, Shiga 525-8577, Japan
Keywords Leptin - Japanese - Physical activity · Peak oxygen uptake $\cdot$ Tri-axial accelerometer

\section{Introduction}

Leptin [1] is primarily expressed by adipose tissue and is one of the major adipocytokines. Recombinant leptin reduces food intake and body weight in both human and mouse models through its effect on the central nervous system [2-4]. In addition, in clinical practice, circulating leptin levels are positively associated with the damage to the arterial walls, obesity, type 2 diabetes mellitus and metabolic syndrome risk factors in both young people and adults [5-8].

It is well known that physical activity and/or physical fitness are closely linked to metabolic disorders [9-11]. Sawada et al. [12] reported that a low cardiorespiratory fitness level is an important risk factor for incidence of type 2 diabetes among Japanese men by prospective cohort study. Sandvik et al. [13] also showed that physical fitness was a graded, independent, long-term predictor of mortality due to cardiovascular causes in healthy, middle-aged men. Taken together, physical activity and/or physical fitness may reduce circulating leptin levels. In fact, we have also showed that exercise education and using pedometer significantly reduced serum leptin levels for up to 1 year of follow-up [14].

Some studies in the literature have reported a relation between circulating leptin levels and physical activity and/ or physical fitness [15-21]. However, neither the link between accurately evaluated circulating leptin levels and physical activity and/or physical fitness nor the combined effect of physical activity and/or physical fitness on circulating leptin levels has not been fully discussed in 
Table 1 Clinical characteristics of the enrolled subjects

\begin{tabular}{|c|c|c|c|c|c|c|}
\hline & \multicolumn{3}{|l|}{ Men } & \multicolumn{3}{|l|}{ Women } \\
\hline & Mean $\pm \mathrm{SD}$ & Minimum & Maximum & Mean \pm SD & Minimum & Maximum \\
\hline Number of subjects & 85 & & & 111 & & \\
\hline Age (years) & $44.0 \pm 9.7$ & 30 & 64 & $46.4 \pm 8.7$ & 30 & 64 \\
\hline Height (cm) & $169.5 \pm 5.4$ & 157.3 & 181.0 & $158.0 \pm 5.3$ & 148.2 & 174.5 \\
\hline Body weight $(\mathrm{kg})$ & $66.6 \pm 8.4$ & 49.9 & 105.3 & $54.1 \pm 8.0$ & 35.3 & 76.4 \\
\hline Body mass index $\left(\mathrm{kg} / \mathrm{m}^{2}\right)$ & $23.1 \pm 2.7$ & 18.2 & 34.3 & $21.6 \pm 3.0$ & 13.2 & 31.3 \\
\hline Abdominal circumference $(\mathrm{cm})$ & $81.8 \pm 8.0$ & 68.5 & 110.8 & $77.1 \pm 8.9$ & 61.5 & 104.3 \\
\hline Peak oxygen uptake $(\mathrm{mL} / \mathrm{kg} / \mathrm{min})$ & $38.1 \pm 8.0$ & 16.5 & 55.8 & $29.5 \pm 5.9$ & 15.0 & 45.2 \\
\hline Physical activity (METs $\mathrm{h} / \mathrm{w}$ ) & $23.4 \pm 15.4$ & 1.19 & 74.1 & $23.4 \pm 12.5$ & 3.5 & 66.4 \\
\hline Systolic blood pressure $(\mathrm{mmHg})$ & $125.0 \pm 12.1$ & 101.0 & 159.0 & $115.2 \pm 12.8$ & 92.0 & 162.0 \\
\hline Diastolic blood pressure $(\mathrm{mmHg})$ & $77.6 \pm 8.1$ & 59.0 & 94.0 & $70.3 \pm 9.6$ & 52.0 & 96.0 \\
\hline \multicolumn{7}{|l|}{ Blood profile } \\
\hline Leptin (ng/mL) & $3.2 \pm 2.3$ & 0.5 & 14.7 & $5.9 \pm 3.8$ & 1.0 & 20.6 \\
\hline Triglyceride $(\mathrm{mg} / \mathrm{dL})$ & $106.1 \pm 74.4$ & 34.0 & 554.0 & $74.0 \pm 35.2$ & 29.0 & 200.0 \\
\hline HDL cholesterol (mg/dL) & $60.4 \pm 18.3$ & 30.0 & 149.0 & $69.2 \pm 12.8$ & 41.0 & 103.0 \\
\hline Blood glucose (mg/dL) & $94.0 \pm 11.3$ & 73.0 & 146.0 & $88.3 \pm 8.3$ & 59.0 & 133.0 \\
\hline $\operatorname{Insulin}(\mu \mathrm{U} / \mathrm{mL})$ & $5.3 \pm 3.6$ & 0.9 & 22.6 & $4.8 \pm 2.7$ & 0.6 & 16.5 \\
\hline HOMA index & $1.3 \pm 1.2$ & 0.2 & 7.9 & $1.1 \pm 0.7$ & 0.1 & 4.0 \\
\hline Energy intake (kcal) & $2111.1 \pm 467.7$ & 1013.4 & 3536.0 & $1663.0 \pm 424.7$ & 686.0 & 3383.3 \\
\hline Number of subjects with smoking habit (\%) & $20(23.5)$ & & & $1(0.9)$ & & \\
\hline
\end{tabular}

METs h/w, $\Sigma$ [metabolic equivalents $\times$ h per week (METs h/w)]; HOMA index, homeostasis model assessment index

apparently healthy Japanese. In addition, the simple effect of physical activity and/or physical fitness without metabolic disorders on circulating leptin levels is needed to be investigated. Therefore, in this cross-sectional study, we evaluated the relationship between circulating leptin levels and physical activity and/or physical fitness in apparently healthy Japanese who were thought to have lower insulin resistance.

\section{Methods}

\section{Subjects}

We used data for 196 subjects (85 men and 111 women) among 1,118 subjects originally enrolled at Okayama Southern Institute of Health, Okayama Health Foundation, Okayama, Japan (256 subjects) and the National Institute of Health and Nutrition, Tokyo, Japan (862 subjects) who met the following criteria: (1) wanted to enroll in the Nutrition and Exercise Intervention Study (NEXIS) at Okayama Southern Institute of Health; (2) had been tested for anthropometric data, physical activity, peak oxygen uptake, blood pressure (BP) measurements and blood examinations including circulating leptin levels; (3) received no medication such as drugs for diabetes, hypertension, or dyslipidemia; and (4) provided written informed consent (Table 1).

Ethical approval for the study was obtained from the Ethical Committee of the Okayama Health Foundation, Okayama, Japan and the National Institute of Health and Nutrition, Tokyo, Japan. This original study protocol was registered in the ClinicalTrials.gov Identifier (NCT00926744).

Blood sampling and assays

After the subjects fasted and rested overnight for 10-12 h, blood samples were collected to determine circulating levels of leptin, high-density lipoprotein (HDL) cholesterol, triglycerides (L Type Wako Triglyceride $\cdot \mathrm{H}$, Wako Chemical, Osaka, Japan), blood glucose and insulin. Circulating leptin levels were measured using a HUMAN LEPTIN RIA (LINCO Research, Inc., USA). Blood glucose was measured by the glucose-oxidant method. Serum insulin was measured by chemiluminescent immunoassay (CLIA) (ABOTT Japan Co. LTD., Tokyo, Japan). Plasma glucose was measured using the glucose-oxidant method. The insulin resistance was evaluated using the homeostasis model assessment (the HOMA index) [fasting plasma glucose $(\mathrm{mg} / \mathrm{dl}) \times$ fasting serum insulin $(\mu \mathrm{U} / \mathrm{ml}) / 405]$, according to the method developed by Matthews et al. [22]. 


\section{Clinical parameters}

Anthropometric parameters, physical activity measured using a tri-axis accelerometer, peak oxygen uptake, systolic BP (SBP), diastolic BP (DBP), cigarette smoking habit and energy intake according to a comprehensive brief-type selfadministered diet history questionnaire (BDHQ) were evaluated as previously described [23] in the NEXIS Study.

\section{Statistical analysis}

All data are expressed as mean \pm SD values. Pearson's correlation coefficients were calculated and used to test the significance of the linear relationship between continuous parameters, where $p<0.05$ was considered statistically significant. Stepwise multiple regression analysis was also performed to test the relationship between circulating leptin levels and other clinical variables.

\section{Results}

The clinical parameters of the enrolled subjects are summarized in Table 1. Circulating leptin levels were $3.2 \pm 2.3 \mathrm{ng} / \mathrm{mL}$ in men and $5.9 \pm 3.8 \mathrm{ng} / \mathrm{mL}$ in women. Physical activity over 3 METs per week evaluated by a triaxis accelerometer was $23.4 \pm 15.4 \mathrm{METs} \mathrm{h} / \mathrm{w}$ in men and $23.4 \pm 12.5 \mathrm{METs} \mathrm{h} / \mathrm{w}$ in women. Peak oxygen uptake was $38.1 \pm 8.0 \mathrm{~mL} / \mathrm{kg} / \mathrm{min}$ in men and $29.5 \pm 5.9 \mathrm{~mL} / \mathrm{kg} /$ min in women (Table 1).

We evaluated the relationship between circulating leptin levels and clinical parameters (Table 2). Circulating leptin levels were significantly and positively correlated with body weight, BMI, abdominal circumference, insulin and the HOMA index in both sexes. Circulating leptin levels were significantly and negatively correlated with peak oxygen uptake in both sexes. In addition, weak relationships between circulating leptin levels and triglycerides or blood glucose in both sexes were noted. There were also weak relationships between circulating leptin levels and HDL cholesterol in men, and between circulating leptin levels and SBP and physical activity evaluated by $\sum[$ metabolic equivalents $\times \mathrm{h}$ per week $(\operatorname{METsh} / \mathrm{w})]$ in women.

Finally, we used stepwise multiple regression analysis to evaluate the effect of clinical parameters, i.e., age, BMI, abdominal circumference, energy intake [24], cigarette smoking, physical activity and peak oxygen uptake on circulating leptin levels, and found that BMI, abdominal circumference, age and peak oxygen uptake were significant in men [Circulating leptin levels $=-6.115+0.259$ $(\mathrm{BMI})+0.109$ (abdominal circumference) -0.050 (age)0.089 (peak oxygen uptake), $\left.r^{2}=0.714, p<0.0001\right]$.
Meanwhile, BMI, abdominal circumference and physical activity (METs h/w) were significant in women [Circulating leptin levels $=-15.979+0.650 \quad(\mathrm{BMI})+0.114$ (abdominal circumference)-0.043 (physical activity), $\left.r^{2}=0.613, p<0.0001\right]$.

\section{Discussion}

In this study, we first evaluated the relationship between circulating leptin levels and physical fitness and/or physical activity using a tri-axial accelerometer in apparently healthy Japanese. Stepwise multiple regression analysis showed that peak oxygen uptake in men and physical activity in women were closely associated with circulating leptin levels even after adjusting for confounding factors.

Leptin-deficient ob/ob mice have decreased activity [25] and pharmacological therapy with leptin increased activity and decreased adiposity [25]. Leptin receptor-deficient $\mathrm{db} /$ $\mathrm{db}$ mice also showed hypoactivity [26]. Murakami et al. [27] investigated the relationship between Q223R polymorphism in the leptin receptor (LEPR) gene and physical activity level, and showed that RR genotype of Q223R polymorphism in the LEPR gene was associated with shorter time spent in light physical activity and longer inactive time in free-living Japanese. In clinical study, Martinez-Gomez et al. [15] reported that vigorous physical activity evaluated by accelerometer for 7 days and cardiorespiratory fitness were inversely associated with leptin in 198 adolescents. Jimenez-Pavon et al. [16] also showed that physical activity and fitness testing were negatively correlated with leptin. Breaks in sedentary time were significantly inversely associated with leptin [17]. However, Franks et al. [18] showed that leptin was significantly associated with physical activity energy expenditure, but not with cardiorespiratory fitness. Higher total or central fat mass was the only predictor of higher plasma leptin, and no other variables, i.e., physical activity energy expenditure and physical fitness added any power to predict [19]. In addition, in some reports, leptin was negatively correlated with maximal oxygen uptake only in men [20, 21]. Therefore, the results of the relationship between circulating leptin levels and physical activity and/or physical fitness varied.

In this study, we accurately evaluated the relationship between circulating leptin levels and physical activity using a tri-axial accelerometer and/or physical fitness in apparently healthy Japanese assumed to be without insulin resistance. Stepwise multiple regression analysis showed that peak oxygen uptake in men and physical activity in women were predictors for circulating leptin levels, as well as BMI and abdominal circumference. The difference in physical fitness and circulating leptin levels between men 
Table 2 Simple correlation analysis between serum leptin levels and clinical parameters

\begin{tabular}{|c|c|c|c|c|}
\hline & \multicolumn{2}{|l|}{ Men } & \multicolumn{2}{|l|}{ Women } \\
\hline & $r$ & $p$ & $r$ & $p$ \\
\hline Age (years) & 0.028 & 0.8004 & 0.072 & 0.4511 \\
\hline Height $(\mathrm{cm})$ & 0.025 & 0.8231 & 0.004 & 0.9702 \\
\hline Body weight (kg) & 0.714 & $<0.0001$ & 0.700 & $<0.0001$ \\
\hline Body mass index $\left(\mathrm{kg} / \mathrm{m}^{2}\right)$ & 0.754 & $<0.0001$ & 0.746 & $<0.0001$ \\
\hline $\begin{array}{l}\text { Abdominal circumference } \\
(\mathrm{cm})\end{array}$ & 0.799 & $<0.0001$ & 0.712 & $<0.0001$ \\
\hline $\begin{array}{l}\text { Peak oxygen uptake } \\
(\mathrm{mL} / \mathrm{kg} / \mathrm{min})\end{array}$ & -0.571 & $<0.0001$ & -0.470 & $<0.0001$ \\
\hline $\begin{array}{l}\text { Physical activity } \\
\text { (METs } \mathrm{h} / \mathrm{w})\end{array}$ & -0.213 & 0.0509 & -0.251 & 0.0079 \\
\hline $\begin{array}{l}\text { Systolic blood pressure } \\
(\mathrm{mmHg})\end{array}$ & 0.196 & 0.0718 & 0.201 & 0.0348 \\
\hline $\begin{array}{l}\text { Diastolic blood pressure } \\
\quad(\mathrm{mmHg})\end{array}$ & 0.057 & 0.6038 & 0.176 & 0.0645 \\
\hline \multicolumn{5}{|l|}{ Blood profile } \\
\hline Triglyceride $(\mathrm{mg} / \mathrm{dL})$ & 0.368 & 0.0005 & 0.365 & $<0.0001$ \\
\hline HDL cholesterol $(\mathrm{mg} / \mathrm{dL})$ & -0.289 & 0.0074 & -0.138 & 0.1483 \\
\hline Blood glucose (mg/dL) & 0.356 & 0.0008 & 0.378 & $<0.0001$ \\
\hline $\operatorname{Insulin}(\mu \mathrm{U} / \mathrm{mL})$ & 0.521 & $<0.0001$ & 0.636 & $<0.0001$ \\
\hline HOMA index & 0.486 & $<0.0001$ & 0.650 & $<0.0001$ \\
\hline Energy intake (kcal) & -0.010 & 0.9277 & -0.078 & 0.4173 \\
\hline
\end{tabular}

Bold values indicate statistical significance $(p<0.05)$

METs h/w, $\Sigma$ [metabolic equivalents $\times \mathrm{h}$ per week (METs $\mathrm{h} / \mathrm{w})$ ]; HOMA index, homeostasis model assessment index

and women may have caused the gender difference in this study. In fact, circulating leptin levels in women were higher than those in men, while peak oxygen uptake in men was higher than that in women. Moro et al. [28] reported that overweight women mobilize more lipids, as assessed by glycerol, than men during exercise, and that the exercise-induced increase in plasma catecholamine levels was lower in women compared with men. Nevertheless, the findings of this study suggest that the effect of physical activity and/or physical fitness on circulating leptin levels is independent of body composition in subjects with lower insulin resistance.

There are some potential limitations in this study. First, our study was cross-sectional rather than longitudinal, so the effects of long-term physical activity and/or physical fitness could not be evaluated clearly. Second, 196 subjects in our study voluntarily underwent measurements: they were, therefore, more likely to be health conscious than an average person. Third, we could not explain the gender difference or a clear mechanism between circulating leptin levels and physical activity and/or physical fitness. In addition to the differences of circulating leptin levels and peak oxygen uptake, sex differences of leptin secretion have shown using adipocytes. Adipocytes in women secreted significantly higher amounts of leptin than those in men by dexamethasone- and estradiol-stimulated conditions [21, 29], suggesting differential regulation of leptin between men and women. However, it seems reasonable to suggest that promoting physical fitness in men and physical activity in women will result in reduced circulating leptin levels in clinical practice. To confirm these findings, ongoing studies are required in the Japanese population.

Acknowledgments This research was supported in part by Research Grants from the Ministry of Health, Labor, and Welfare of Japan. The authors thank Dr. Takeyuki Numata at Okayama Southern Institute of Health, Okayama Health Foundation, Okayama, Japan for his great contribution to this study.

Conflict of interest The authors declare no conflict of interest.

\section{References}

1. Zhang Y, Proenca R, Maffei M, Barone M, Leopold L, Friedman JM. Positional cloning of the mouse obese gene and its human homologue. Nature. 1994;372:425-32.

2. Farooqi IS, Jebb SA, Langmack G, Lawrence E, Cheetham $\mathrm{CH}$, Prentice AM, et al. Effects of recombinant leptin therapy in a child with congenital leptin deficiency. $N$ Eng J Med. 1999;341:879-84.

3. Campfield LA, Smith FJ, Guisez Y, Devos R, Burn P. Recombinant mouse $\mathrm{OB}$ protein: evidence for a peripheral signal linking adiposity and central neural networks. Science. 1995;269:546-9.

4. Tang-Christensen M, Havel PJ, Jacobs RR, Larsen PJ, Cameron JL. Central administration of leptin inhibits food intake and activates the sympathetic nervous system in rhesus macaques. J Clin Endocrinol Metab. 1999;84:711-7.

5. van Dielen FM, van't Veer C, Buurman WA, Greve JW. Leptin and soluble leptin receptor levels in obese and weight-losing individuals. J Clin Endocrinol Metab. 2002;87:1708-16.

6. Qasim A, Mehta NN, Tadesse MG, Wolfe ML, Rhodes T, Girman C, et al. Adipokines, insulin resistance, and coronary artery calcification. J Am Coll Cardiol. 2008;52:231-6.

7. Morales A, Wasserfall C, Brusko T, Carter C, Shatz D, Silverstein $\mathrm{J}$, et al. Adiponectin and leptin concentrations may aid in discriminating disease forms in children and adolescents with type 1 and type 2 diabetes. Diabetes Care. 2004;27:2010-4.

8. Larsson H, Elmstahl S, Ahren B. Plasma leptin levels correlate to islet function independently of body fat in postmenopausal woman. Diabetes. 1996;45:1580-4.

9. Miyatake N, Takahashi K, Wada J, Nishikawa H, Morishita A, Suzuki H, et al. Daily exercise lowers blood pressure and reduces visceral fat in overweight Japanese men. Diabetes Res Clin Pract. 2003;62:149-57.

10. Miyatake N, Nishikawa H, Morishita A, Kunitomi M, Wada J, Suzuki H, et al. Daily walking reduces visceral adipose tissue areas and improves insulin resistance in Japanese obese subjects. Diabetes Res Clin Pract. 2002;58:101-7.

11. Yamanouchi K, Shinozaki T, Chikada K, Nishikawa T, Ito K, Shimizu S, et al. Daily walking combined with diet therapy is a useful means for obese NIDDM patients not only to reduce body weight but also to improve insulin sensitivity. Diabetes Care. $1995 ; 18: 775-8$. 
12. Sawada SS, Lee IM, Muto T, Matsuzaki K, Blair SN. Cardiorespiratory fitness and the incidence of type 2 diabetes: prospective study of Japanese men. Diabetes Care. 2003;26:2918-22.

13. Sandvik L, Erikssen J, Thaulow E, Erikssen G, Mundal R, Rodahl K. Physical fitness as a predictor of mortality among healthy, middle-aged Norwegian men. N Engl J Med. 1993;328:533-7.

14. Miyatake N, Takahashi K, Wada J, Nishikawa H, Morishita A, Suzuki $\mathrm{H}$, et al. Changes in serum leptin concentrations in overweight Japanese men after exercise. Diabetes Obes Metab. 2004;6:332-7.

15. Martinez-Gomez D, Eisenmann JC, Gomez-Martinez S, Veses A, Romeo J, Veiga OL, AFINOS Study Group, et al. Associations physical activity and fitness with adipocytokines in adolescents: the AFINOS Study. Nutr Metab Cardiovasc Dis. 2012;22:252-9.

16. Jimenez-Pavon D, Ortega FB, Artero EG, Labayen I, VicenteRodriguez G, Huybrechts I, HELENA Study Group, et al. Physical activity, fitness, and serum leptin concentrations in adolescents. J Pediatr. 2012;160:598-603.

17. Henson J, Yates T, Edwardson CL, Khunti K, Talbot D, Gray LJ, et al. Sedentary time and markers of chronic low-grade inflammation in a high risk population. PLoS One. 2013;8:e78350.

18. Franks PW, Farooqi IS, Luan J, Wong MY, Halsall I, O'Rahilly $\mathrm{S}$, et al. Does physical activity energy expenditure explain the between individual variation in plasma leptin concentrations after adjusting for differences in body composition? J Clin Endocrinol Metab. 2003;88:3258-63.

19. St-Pierre DH, Faraj M, Karelis AD, Conus F, Henry JF, St-Onge $\mathrm{M}$, et al. Lifestyle behaviours and components of energy balance as independent predictors of ghrelin and adiponectin in young non-obese women. Diabetes Metab. 2006;32:131-9.

20. Maimoun L, Simar D, Caillaud C, Coste O, Puech AM, Jaussent A, et al. Basal plasma leptin levels in healthy elderly males are related to physical fitness without impact on bone metabolism. J Sports Med Phys Fitness. 2011;51:160-8.
21. Miller GD, Frost R, Olive J. Relation of plasma leptin concentrations to sex, body fat, dietary intake, and peak oxygen uptake in young adult women and men. Nutrition. 2001;17:105-11.

22. Matthews DR, Hosker JP, Rudenski AS, Naylor BA, Treacher DF, Turner RC. Homeostasis model assessment: insulin resistance and $\beta$-cell function from fasting plasma glucose and insulin concentrations in man. Diabetologia. 1985;28:412-9.

23. Miyatake N, Numata T, Murakami H, Kawakami R, Sanada K, Tabata I, et al.: Circulating adiponectin levels are associated with peak oxygen uptake in Japanese. Environ Health Prev Med. 2014;19:279-85.

24. Koutsari C, Karpe F, Humphereys SM, Frayn KN, Hardman AE. Plasma leptin is influenced by diet composition and exercise. Int J Obes Relat Metab Disord. 2003;27:901-6.

25. Pelleymouter MA, Cullen MJ, Barker MB, Hecht R, Winters D, Boone T, et al. Effects of the obese gene product on body weight regulation in ob/ob mice. Science. 1995;269:540-3.

26. Coppari R, Ichinose M, Lee CE, Pullen AE, Kenny CD, McGovern RA, et al. The hypothalamic arcuate nucleus: a key site for mediating leptin's effects on glucose homeostasis and locomotor activity. Cell Metab. 2005;1:63-72.

27. Murakami H, Iemitsu M, Fuku N, Sanada K, Gando Y, Kawakami R, et al. The Q223R polymorphism in the leptin receptor associates with objectively measured light physical activity in free-living Japanese. Physiol Behav. 2014;129:199-204.

28. Moro C, Pillard F, de Glisezinski I, Crampes F, Thalamas C, Harant I, et al. Sex differences in lipolysis-regulating mechanisms in overweight subjects: effect of exercise intensity. Obesity (Silver Spring). 2007;15:2245-55.

29. Casabiell X, Pineiro V, Peino R, Lage M, Camina J, Gallego R, et al. Gender differences in both spontaneous and stimulated leptin secretion by human omental adipose tissue in vitro: dexamethasone and estradiol stimulate leptin release in women, but not in men. J Clin Endocrinol Metab. 1998;83:2149-55. 